\title{
Electronic brachytherapy for treatment of non-melanoma skin cancers: clinical results and toxicities
}

\author{
Uma Goyal, MD*, Michael K. Cheung, MD²*, Justin Suszko, MD³, Brady Laughlin, MD, Yongbok Kim, PhD5, \\ Jeanette Askam, BS ${ }^{5}$, Hina Arif-Tiwari, MD6, Benjamin Slane, MD , John Gordon, MS ${ }^{8}$, Baldassare Stea, MD, PhD ${ }^{5}$ \\ *Uma Goyal and Michael K. Cheung contributed equally to this work.
}

'Banner MD Anderson Cancer Center and University of Arizona, Phoenix, USA, ² Veterans Affair West Los Angeles Healthcare System, Radiation Oncology, Los Angeles, USA, ${ }^{3}$ RadiantCare, Lacey, USA, ${ }^{4}$ Department of Radiation Oncology. Mayo Clinic, Phoenix, USA, ${ }^{5}$ Department of Radiation Oncology, Banner University Medical Center Tucson, USA, ${ }^{6}$ Department of Medical Imaging, Banner University Medical Center, Tucson, USA, ${ }^{2}$ Lawrence Cancer Center, Radiation Oncology, Lawrence, USA, ${ }^{8}$ Intermountain Healthcare, Salt Lake City, USA

\begin{abstract}
Purpose: Although surgical approaches are standard for most non-melanomatous skin cancers, some patients are not candidates due to medical co-morbidities or functional or cosmetic or lesion location. High-dose-rate electronic brachytherapy (HDR-EBT) may be an alternative treatment modality.

Material and methods: A retrospective chart review was conducted from April 2011 to April 2013. All lesions were pathologically confirmed as malignant basal cell or squamous cell carcinoma. A HDR-EBT system delivered a median biological equivalent dose of $50 \mathrm{~Gy}$ total to a depth of $0.1-0.5 \mathrm{~cm}$ using various sizes of applicators. Treatment feasibility, acute and late toxicity, cosmetic outcomes, and local recurrence were assessed.

Results: Thirty-three patients with a mean age of 76 years with 50 cutaneous lesions were treated. Locations included 17 extremity lesions and 33 head and neck lesions. After treatments, acute grade 3 moist desquamation developed in 9 of the lesions (18\%). Acute grade 4 ulceration developed in 3 lesions in the lower extremity (6\%) and 1 upper lip lesion $(2 \%)$. These toxicities were improved after a median of 20 days. Amongst the 4 lesions with grade 4 toxicities, a greater proportion were in lower extremity lesions compared to head and neck lesions ( $75 \%$ vs. $25 \%)$. There was no difference in the rate of grade 3 and 4 toxicities between patients aged $\leq 75$ years and aged $>75$ years $(p=0.082)$. With a mean long-term follow-up of 45.6 months, there was 1 local recurrence treated with surgery and no reported late toxicities.

Conclusions: Our experience with HDR-EBT for non-melanomatous skin cancers is encouraging in terms of efficacy and convenience for patients. Our long-term follow-up shows a good response in all treated sites. Caution should be
\end{abstract} used for extremity sites, and more fractionated regimens should be considered to avoid severe acute toxicities.

J Contemp Brachytherapy 2021; 13, 5: 497-503 DOI: https://doi.org/10.5114/jcb.2021.109753

Key words: electronic brachytherapy, toxicities, clinical.

\section{Purpose}

Non-melanomatous skin cancers are the most common malignant neoplasms worldwide, and the incidence of skin cancer is increasing rapidly, with an estimated 2-3 million new cases of non-melanoma skin cancers occurring each year [1-4]. Approximately 95\% of all non-melanomatous skin cancers are accounted for by basal cell carcinoma (BCC) and squamous cell carcinomas (SCC) [1]. BCCs occur more frequently than SCCs, comprising approximately $80 \%$ of all non-melanomatous skin cancers, while SCCs have a generally more aggres- sive behavior than BCC and have a higher potential for metastatic spread $[1,5]$. The median age of patients developing basal or squamous cell skin cancers is 68 years, and the most common predisposing factor is prior ultraviolet radiation exposure [6, 7]. Though they are fortunately rarely lethal, non-melanomatous skin cancers can be disfiguring when they occur in cosmetically sensitive locations, particularly on the head and face [8].

Multiple modalities of treatment have been developed for non-melanomatous skin cancers, but surgical excision remains the gold standard and preferred modal- 
ity in most cases. However, some patients may be poor candidates for surgical intervention, particularly the elderly and patients receiving anticoagulation. Additionally, the location and size of the skin lesion can hinder an adequate surgical approach that would otherwise result in unacceptable cosmetic or functional outcomes, primarily in areas around the nose, lip, eyelids, medial canthus, and pinna [5, 8-16]. As such, these patients may be potential candidates for radiation therapy (RT) as an alternative primary treatment modality. Radiation therapy continues to have a role in the adjuvant setting in cases of positive surgical margins, perineural spread, invasion of bone and cartilage, lymph node metastasis, and extensive skeletal muscle infiltration [6].

Previous radiation options have included the use of superficial (orthovoltage) X-rays which have recently become unavailable. In addition, these orthovoltage X-ray techniques are poorly suited for treatment of irregular surfaces, such as the pinna and nasolabial fold, where small SSDs could result in large dose inhomogeneities [17]. Alternatively, megavoltage electron beam therapy can be used but fields may be difficult to shape because of the thickness of the blocks needed for dose conformality [17] and also because this technique requires treatments to be done en-face. Additionally, achieving a 100\% dose at the skin with electrons may require bolus use, and megavoltage energies may cause penetration of deeper normal structures. High-dose-rate (HDR) brachytherapy skin applicators have been shown to be an effective option but limited by the availability of high activity radioactive isotopes [18]. In contrast, HDR electronic brachytherapy (HDR-EBT) technique allows administration of radiation for non-melanomatous skin cancer without use of a radioactive isotope; its low energy beam alleviates the concern for radiation protection. Because the HDR-EBT technique is mobile, it can operate in locations where no well-shielded vault exists and multiple rooms are allotted for HDR-EBT procedures.

Guinot et al. [19] mentioned that low-dose-rate (LDR) is no longer used given the logistics required for LDR application. HDR and pulsed-dose-rate (PDR) have advantages over external beam RT including hypofractionation which does not require daily treatments, HDR and PDR have a short treatment delivery time, and the rapid dose fall-off allows for normal tissue sparing. Balgobind et al. [20] noted that PDR combines physical advantages of HDR with radiobiological advantages of LDR. Fritz et al. [21] reviewed long-term results of PDR for skin metastases from breast cancer, which showed 83-89\% local control and 52\% moist desquamation. However, most patients had received prior external beam RT.

Here we report on a retrospective review of patients treated for BCCs and SCCs with the primary objective of determining the safety, efficacy, cosmetic outcomes, and local recurrence of the HDR-EBT technique.

\section{Material and methods}

All patients treated for malignant non-melanomatous skin cancers with HDR-EBT between April 2011 and April 2013 were identified and a retrospective chart re- view was performed with approval by our institutional review board. All patients had pathologic confirmation of a malignant non-melanomatous skin cancer (BCC or SCC) prior to radiation treatments.

\section{Treatment setup}

Patients were commonly simulated on-machine with the clinical setup in the treatment position using VacLock Bags (Civco, Orange City, IA) for immobilization or more rarely had CT scan-based simulation using a customized thermoplastic mask (Civco, Orange City, IA) for immobilization. For HDR-EBT, we used the Xoft Axxent System device (iCAD, Inc., San Jose, CA). We followed the AAPM TG-61 protocol and used a parallel plate ion chamber that has a calibration factor provided by an Accredited Dosimetry Calibration Laboratory at the University of Wisconsin. This calibration factor was provided at $2 \mathrm{X}$-ray energies.

Each lesion was measured and the gross tumor volume (GTV) was defined as the visible surface lesion. Patients were treated using $1 \mathrm{~cm}, 2 \mathrm{~cm}, 3.5 \mathrm{~cm}$, or $5 \mathrm{~cm}$ applicators to a depth of $0.1-0.5 \mathrm{~cm}$ (determined from the biopsy report or physical examination). An appropriate surface applicator was selected for each lesion to ensure adequate coverage of the clinical and planning target volume, which was defined as the GTV plus an acceptable margin (approximately $1 \mathrm{~cm}$ ) to account for microscopic disease, measurement uncertainty, and setup uncertainty [22] at the discretion of the treating physician. Appropriate measures of protection were used for setup and treatments as needed.

\section{Treatment delivery}

The HDR-EBT system delivered a planned median biologically equivalent dose in $2 \mathrm{~Gy} /$ fraction (fx) of $50 \mathrm{~Gy}$ total (calculated using an $\alpha / \beta=10$ ) with total doses delivered ranging from 5.2 to $58.0 \mathrm{~Gy} / 2-29 \mathrm{fx}$. The prescription dose was an extrapolation from NCCN guideline recommendations [23] and the treating physician's discretion. Patients were treated with several different fractionation regimens depending on the location and depth of the lesion and patient availability, with the most frequent regimen being $40 \mathrm{~Gy} / 8 \mathrm{fx}$, delivered twice weekly over 4 weeks. Different fractionations were used based on treating physician discretion related to proximity to normal structures, tumor location, and availability of the patient.

With each patient's verbal and written permission, all patients were photographed at the time of simulation and assessed before each treatment to ensure that the surface applicator completely covered the skin lesion with adequate margins.

If skin toxicities showed up, patients were treated with topical emollients, silver sulfadiazine, and/or topical steroids at the discretion of the treating physician.

\section{Endpoints}

Endpoints included acute and late toxicities and short-term and long-term efficacy. Mean short-term 
(acute) follow-up was 6 months and long-term follow-up was 45.6 months (1-117 months). Adverse events were assessed during treatment and subsequent follow-up visits and were graded according to the RTOG/EORTC Acute/Late Radiation Morbidity Scoring Criteria. Longterm follow-up was used to assess local recurrence and late toxicities.

\section{Statistics}

Acute toxicity grading was organized into contingency tables and formatted into matrices by demographic, pathologic and treatment characteristics. Fisher's exact test was used to determine the presence of significant associations between categorical variables. The one-way ANOVA test was used to assess for significant differences in mean age, lesion size, and treatment duration by toxicity grade categories (grade $<3$, grade 3 , and grade 4 ). All data were analyzed using Intercooled Stata (version 8.0, Stata Corporation, College Station, TX) and SAS (version 6.12 , SAS, Inc., Cary, NC). Statistical significance was considered as $p<0.05$.

\section{Results}

\section{Patient and lesion demographics}

Thirty-three patients with 50 non-melanoma cutaneous cancers were treated using the HDR-EBT technique between April 2011 and April 2013. Demographic information is shown in Table 1. Mean age was 76 years (range 43-92 years). Seventy-six percent of patients were treated in the definitive setting and $24 \%$ were treated for recurrent disease after surgery. Lesion locations included 17 extremity lesions and 33 head and neck lesions, which encompassed 1 (2\%) scalp, 11 (22\%) face, 17 (34\%) nose, $1(2 \%)$ ear, and $3(6 \%)$ around eyes.

Most treated extremity lesions were located in the distal lower extremity, affecting the shin, calf, or ankle. One extremity lesion was treated in the upper arm.

\section{Treatment specifics}

The mean and median lesion sizes were $0.98 \mathrm{~cm}$ and $1 \mathrm{~cm}$, respectively. The standard deviation of the lesions' sizes is 0.5838 . Most patients $(72 \%)$ were treated with at least a $1 \mathrm{~cm}$ margin around the tumor and median margin distance of $1.5 \mathrm{~cm}$ from the visible lesion. Smaller margins were used in cases where organs at risk were in close proximity to the treated lesion. A breakdown of the applicator sizes, treatment depths, and treatment margins by tumor size is shown in Table 2. The mean treatment time per fx was 5.5 minutes (range 1.8-14.2 minutes).

Alternate fractionation regimens were used in settings where patients had a history of prior radiation $(n=8)$ or concerns over toxicity to a nearby organ at risk $(n=17)$. Treatments were delivered over a mean of 26.8 days (range 2-96 days). Eight lesions were treated over $>30$ days.

There was 1 patient who started treatment but did not complete the HDR-EBT course and 9 patients who had treatment breaks during HDR-EBT.
Table 1. Patient and lesion demographics

\begin{tabular}{lcc} 
Variable & $n$ & $\%$ \\
\hline Histology & 28 & 56.0 \\
\hline Basal cell & 22 & 44.0 \\
\hline Squamous cell & & \\
\hline \begin{tabular}{l} 
Treatment setting \\
\hline Definitive
\end{tabular} & 38 & 76.0 \\
\hline Recurrence & 12 & 24.0 \\
\hline Gender & & \\
\hline Female & 28 & 56.0 \\
\hline Male & 22 & 44.0 \\
\hline Lesion location & 33 & \\
\hline Head and neck & 1 & 2.0 \\
\hline Scalp & 11 & 22.0 \\
\hline Face & 17 & 34.0 \\
\hline Nose & 1 & 2.0 \\
\hline Ear & 3 & 6.0 \\
\hline Around eyes & 17 & 34.0 \\
\hline Extremity & & \\
\hline
\end{tabular}

Table 2. Applicator characteristics and lesion size

\begin{tabular}{lcc} 
Applicator size & $n$ & Median lesion size \\
\hline $1 \mathrm{~cm}$ & 3 & $0.50 \mathrm{~cm}$ \\
\hline $2 \mathrm{~cm}$ & 27 & $1.00 \mathrm{~cm}$ \\
\hline $3.5 \mathrm{~cm}$ & 13 & $1.00 \mathrm{~cm}$ \\
\hline $5 \mathrm{~cm}$ & 7 & $1.40 \mathrm{~cm}$ \\
\hline Treatment depth & & \\
\hline $0.1 \mathrm{~cm}$ & 11 & $0.50 \mathrm{~cm}$ \\
\hline $0.2 \mathrm{~cm}$ & 18 & $1.00 \mathrm{~cm}$ \\
\hline $0.3 \mathrm{~cm}$ & 14 & $1.00 \mathrm{~cm}$ \\
\hline $0.4 \mathrm{~cm}$ & 3 & $0.40 \mathrm{~cm}$ \\
\hline $0.5 \mathrm{~cm}$ & 4 & $1.00 \mathrm{~cm}$ \\
\hline Margin & & \\
\hline$\leq 0.5 \mathrm{~cm}$ & 8 & $1.50 \mathrm{~cm}$ \\
\hline$>0.5-1 \mathrm{~cm}$ & 13 & $1.00 \mathrm{~cm}$ \\
\hline$>1-1.5 \mathrm{~cm}$ & 7 & $0.50 \mathrm{~cm}$ \\
\hline$>1.5 \mathrm{~cm}$ & 22 & $0.90 \mathrm{~cm}$
\end{tabular}

\section{Incidence and management of acute complications}

All patients developed grade 1 toxicity with erythema and $28 \%$ of patients developed grade 2 toxicity with patchy moist desquamation. However, 13 (39\%) patients progressed to grade 3 toxicity with confluent moist desquamation or grade 4 toxicity with ulceration. Acute grade 3 moist desquamation developed in 9 of the treated 
lesions (18\%) and acute grade 4 ulceration developed in 3 lesions in the lower extremity $(6 \%)$ and 1 lesion on the upper lip (2\%). Amongst the four grade 4 toxicities, 2 lesions were $0.2 \mathrm{~cm}$ deep and 2 lesions were $0.4 \mathrm{~cm}$ deep. Nine patients were started on pentoxifylline $400 \mathrm{mg}$ by mouth 3 times daily and vitamin E 400 IU daily. One patient underwent debridement and a free-flap reconstruction for a non-healing ulcer on the shin. Nine patients had treatment breaks with a median duration of 8 days (range, 2-55 days). Grade 2 and higher toxicities were typically observed near the end of the treatment course and lasted a median of 20 days (range, 1-49 days). The distribution of acute toxicities is tabulated along with demographic and treatment characteristics in Tables 3 and 4, respectively.

As noted in Table 3, 18\% of patients treated for extremity lesions experienced grade 4 skin ulceration, which was significantly more frequent than $3 \%$ among the head and neck lesions $(p=0.014)$. Conversely, patients treated to the head and neck developed confluent moist desquamation more frequently than the extremity lesions but did not progress to ulceration ( $27 \%$ vs. $0 \%$, $p=0.014)$. Larger lesions were also associated with a higher proportion of patients progressing to grade 3 ( $9 \%$ vs. $40 \%$ ) and grade 4 toxicity ( $6 \%$ vs. $13 \%, p=0.013)$, compared to smaller lesions. However, there was no difference in the distributions of toxicities based on age between patients $\leq 75$ years of age and those aged $>75(p=0.082)$. Fur- thermore, patients more frequently progressed to grade 4 ulceration when treated with $\geq 5$ Gy per fx $(11 \%$ vs. $0 \%$, $p=0.003)$ and with overall treatment duration less than 25 days $(12 \%$ vs. $4 \%, p=0.018)$. These data are presented in Table 4.

One patient developed ulceration at 102 days after completing treatment for an SCC on the left posteromedial ankle. She was treated with Unna boot dressings and pentoxifylline with vitamin $\mathrm{E}$ administered.

\section{Long-term efficacy}

At a mean follow-up of 45.6 months, there was 1 local recurrence recorded. This patient was treated with a wide local excision 35 months after completing HDREBT. There were no recorded late toxicities.

\section{Discussion}

Several non-surgical modalities have long been available for the treatment of non-melanomatous skin cancers, but the reduced shielding requirements, convenience of treatment (less than 6 minutes per $\mathrm{fx}$ in our experience), and relative mobility of HDR-EBT have made this modality an attractive alternative to superficial and orthovoltage X-rays, electron beam, and isotope-based HDR brachytherapy. However, there remains limited data available on the clinical experience of this treatment technique.

Table 3. Demographics and acute toxicity data

\begin{tabular}{|c|c|c|c|c|c|}
\hline Parameter & Total & $\begin{array}{c}\text { Grade }<3 \\
(n=37)\end{array}$ & $\begin{array}{l}\text { Grade } 3 \\
(n=9)\end{array}$ & $\begin{array}{l}\text { Grade } 4 \\
(n=4)\end{array}$ & $\begin{array}{c}\text { Fisher's exact } \\
p \text {-value }\end{array}$ \\
\hline \multicolumn{6}{|l|}{ Age } \\
\hline Mean & $76 \pm 4.8$ & $74 \pm 1.8$ & $69 \pm 3.6$ & $80 \pm 0.9$ & $0.22^{\star}$ \\
\hline Median & 76 & 75 & 64 & 80 & \\
\hline$\leq 75$ years & 25 & $19(76 \%)$ & $6(24 \%)$ & $0(0 \%)$ & 0.082 \\
\hline$>75$ years & 25 & $18(72 \%)$ & $3(12 \%)$ & $4(16 \%)$ & \\
\hline \multicolumn{6}{|l|}{ Gender } \\
\hline Female & 28 & $23(82 \%)$ & $1(4 \%)$ & 4 (14\%) & 0.002 \\
\hline Male & 22 & $14(64 \%)$ & $8(36 \%)$ & $0(0 \%)$ & \\
\hline \multicolumn{6}{|l|}{ Location } \\
\hline Head and neck & 33 & $23(70 \%)$ & $9(27 \%)$ & $1(3 \%)$ & 0.014 \\
\hline Extremity & 17 & $14(82 \%)$ & $0(0 \%)$ & $3(18 \%)$ & \\
\hline \multicolumn{6}{|l|}{ Histology } \\
\hline Basal & 28 & $21(75 \%)$ & $6(21 \%)$ & $1(4 \%)$ & 0.437 \\
\hline Squamous & 22 & $16(73 \%)$ & $3(14 \%)$ & $3(14 \%)$ & \\
\hline \multicolumn{6}{|l|}{ Lesion size } \\
\hline Mean & $0.98 \pm 0.8$ & $0.88 \pm 0.9$ & $1.38 \pm 2.1$ & $0.95 \pm 3.2$ & $0.073^{*}$ \\
\hline Median & 1.0 & 0.9 & 1.5 & 0.95 & \\
\hline$\leq 1 \mathrm{~cm}$ & 35 & $30(86 \%)$ & $3(9 \%)$ & $2(6 \%)$ & 0.013 \\
\hline$>1 \mathrm{~cm}$ & 15 & $7(47 \%)$ & $6(40 \%)$ & $2(13 \%)$ & \\
\hline
\end{tabular}


Table 4. Treatment characteristics and acute toxicity data

\begin{tabular}{|c|c|c|c|c|c|}
\hline Parameter & Total & $\begin{array}{c}\text { Grade }<3 \\
(n=37)\end{array}$ & $\begin{array}{c}\text { Grade } 3 \\
(n=9)\end{array}$ & $\begin{array}{c}\text { Grade } 4 \\
(n=4)\end{array}$ & $\begin{array}{c}\text { Fisher's exact } \\
p \text {-value }\end{array}$ \\
\hline \multicolumn{6}{|l|}{ \# Fractions } \\
\hline$\leq 8$ & 38 & $29(76 \%)$ & $5(13 \%)$ & $4(11 \%)$ & 0.180 \\
\hline$>8$ & 12 & $8(67 \%)$ & $4(33 \%)$ & $0(0 \%)$ & \\
\hline \multicolumn{6}{|l|}{ Fraction size } \\
\hline$<5 \mathrm{~Gy}$ & 16 & $9(56 \%)$ & 7 (44\%) & $0(0 \%)$ & 0.003 \\
\hline$\geq 5 \mathrm{~Gy}$ & 34 & $28(82 \%)$ & $2(6 \%)$ & $4(12 \%)$ & \\
\hline \multicolumn{6}{|l|}{ Total EQD ${ }_{2}^{\ddagger}$} \\
\hline$<50 \mathrm{~Gy}$ & 12 & $8(67 \%)$ & $4(33 \%)$ & $0(0 \%)$ & 0.180 \\
\hline$\geq 50$ Gy & 38 & $29(76 \%)$ & $5(13 \%)$ & $4(11 \%)$ & \\
\hline \multicolumn{6}{|c|}{ Treatment duration } \\
\hline Mean & $26.8 \pm 2.1$ & $24.4 \pm 1.9$ & $38.2 \pm 8.1$ & $23.5 \pm 2.6$ & $0.037^{\star}$ \\
\hline Median & 24 & 24 & 26 & 22 & \\
\hline$<25$ days & 26 & $22(85 \%)$ & $1(5 \%)$ & $3(12 \%)$ & 0.018 \\
\hline$\geq 25$ days & 24 & $15(63 \%)$ & $8(33 \%)$ & $1(4 \%)$ & \\
\hline
\end{tabular}

"ANOVA; ${ }^{*} E Q D_{2}$ - equivalent dose in 2 Gy fractions $(\alpha / \beta=10)$; bold is significant

Ouhib et al. [24] described HDR brachytherapy including molds/surface applicators and interstitial options as well as HDR-EBT. For molds/surface applicators, dosing with $40 \mathrm{~Gy}$ in $8 \mathrm{fx}$ was recommended. Tom et al. [25] discussed the American Brachytherapy Society consensus regarding HDR-EBT to reserve its use for clinical trials given the lack of data comparing HDR-EBT to traditional RT techniques and lack of long term follow-up. However, GEC-ESTRO does provide HDR-EBT as a treatment option for skin brachytherapy [19]. Shah et al. [26] discussed radionuclide-based skin brachytherapy for non-melanomatous skin cancers as a standard of care option. Gauden et al. [27] reported that the use of HDR brachytherapy with a Leipzig surface applicator had acute grade 1 toxicity of $71 \%$ and grade 2 was $34 \%$. Late hypopigmentation toxicity was $5.5 \%$. Therefore, toxicities from HDR brachytherapy appear to be similar to our experience with HDR-EBT. According to GEC-ESTRO, 5 Gy $\times 8 \mathrm{fx}$ or $7 \mathrm{~Gy} \times 6 \mathrm{fx}$ twice a week was recommended for brachytherapy with surface applicators. Also, they stated that brachytherapy provides an efficient and well-tolerated treatment for skin cancer patients [19]. This tolerable dose and fractionation are similar to the findings of our study. However, there is controversy in recommendations regarding HDR-EBT use for non-melanomatous skin cancers.

Because HDR-EBT is a contact therapy, it is susceptible to potential under-dosing of the lesions if they are not accurately targeted. Our institutional protocol treated patients with a setup margin of at least $1 \mathrm{~cm}$ around the boundary of the gross lesion with smaller margins used when constrained by nearby critical structures. The smallest margin was $2 \mathrm{~mm}$ and it was for a left malar BCC due to proximity to normal tissue structures. We do not believe this affected the overall results. Since then, more detailed recommendations on lateral margins have been published by Khan et al. [28], based on frozen section evaluation of the microscopic extent of disease to help guide clinician determination of tumor volumes. However, determination of the deep margin remains a concern since clinical assessment alone may not be accurate and remains an area for investigation. A report by Ballester-Sánchez et al. [29] suggested using high-frequency ultrasound to assess tumor depth; however, they found a borderline significant correlation between ultrasound-determined and punch biopsy-determined depth for superficial lesions ( $p=0.05007)$, but no correlation for nodular lesions.

In terms of treatment tolerance, our experience has shown no statistically significant difference in the incidence of toxicities between patients aged $\leq 75$ years and aged $>75$ years, and this is consistent with prior published reports using the HDR-EBT technique for skin cancers [30,31]. Most patients in our cohort developed no worse toxicity than grade 2 with patchy moist desquamation. However, while not statistically significant, it may be clinically relevant that the four grade 4 toxicities in our study occurred in patients aged $>75$ years.

Furthermore, lesions in the lower extremity, particularly on the shin, are known to have poor vascularity and are associated with poor healing after surgical therapy or RT. Indeed, several older series have reported poor wound healing to affect up to $33 \%$ of patients treated with RT to the lower extremity [32-34]. A recent study using HDR-EBT by Ballester-Sánchez et al. [31] found that $100 \%$ of their trunk and extremity cases developed ulceration compared to $44.4 \%$ in the head and neck. Our study compares favorably with $18 \%$ of extremity lesions developing ulceration, but this rate was still significantly more than the $3 \%$ incidence in our head and neck lesions 
$(p=0.014)$. As such, it may be prudent to consider more fractionated regimens, such as $40 \mathrm{~Gy}$ in 8-10 fx twice weekly, when confronted with the treatment of an extremity lesion, particularly in elderly patients.

We had 1 patient who did not complete the prescribed HDR-EBT treatment. The range of completed fractions was included to provide information on a likely clinical population with some patients who may not complete treatment on their own accord and had acute grade 0 toxicity. Based on our prior experience, $40 \mathrm{~Gy}$ in $10 \mathrm{fx}$ seemed to be well tolerated and effective at short term follow-up [35], and $40 \mathrm{~Gy}$ in $8 \mathrm{fx}$ was the most common regimen used in this study's patient cohort.

Since all patients in our study developed some amount of skin toxicity during treatment, patients were routinely treated with topical agents as part of their skin care regimen to reduce the severity of radiation-induced dermatitis and promote healing. Although the medical literature includes a myriad of studies evaluating treatments for radiation dermatitis, it has not been able to furnish clinicians with an optimal skin care regimen [36, 37]. As such, our institution generally recommended patients start with an aqueous cream or petroleum-based emollient before escalating to more aggressive skin care regimens such as topical steroids or silver sulfadiazine based on data extrapolated from the treatment of radiation dermatitis in breast irradiation [38-40]. Two randomized trials by Boström et al. and Hindley et al. showed significant reduction in radiation dermatitis with use of topical mometasone furoate, while topical silver sulfadiazine was supported by another randomized trial by Hemati et al. [38-40]. Pentoxifylline and vitamin E was prescribed in 9 patients in our cohort, including 3 patients who developed ulceration, with the intent of promoting healing and preventing late toxicities such as radiation-induced fibrosis, as supported by several studies [41-44]. However, pentoxifylline has not been found to affect acute radiation skin reactions or pain $[45,46]$.

The limitations of this study include its retrospective nature and limited number of patients assessed. However, our study does contribute to the growing literature on HDR-EBT by confirming its promising short-term and long-term efficacy and reporting our acute toxicity experience. Unfortunately, there remains a paucity of long-term data on both the safety and efficacy of HDREBT, but our data provide a long-term follow-up of 45.6 months. The acute grade 3 and 4 toxicities were treated in our patient population and there were no recorded late toxicities. Toxicities from HDR brachytherapy appear to be similar to HDR-EBT. Roth et al. [47] found that almost $99 \%$ of non-melanomatous skin cancers will not recur after 85 months following superficial RT. Our study has a median follow-up of 45.6 months, so this may not be a long enough follow-up for local recurrence of non-melanomatous skin cancers, in which case further long-term data are warranted.

The series by Bhatnagar et al. [30] has a mean follow-up of 10 months' duration, which likely is not adequate to assess the risk of recurrence and late sequelae. A retrospective study of 180 cutaneous SCCs by Barysch et al. [48] found that with superficial radiation, the re- lapse-free survival declines from $95.8 \%$ at 1 year to $80.4 \%$ at 10 years, illustrating the need for longer follow-up to evaluate efficacy of radiation modalities such as HDREBT for non-melanomatous skin cancers. Following our initial experience with grade 4 toxicities, we began to measure the depth of each lesion with high frequency ultrasound (US) [49]. By using US-guided depth measurements that allow for a more accurate depth measurement to reduce the surface skin dose, we have not had another grade 4 toxicity in subsequent patients [22].

\section{Conclusions}

Our experience with HDR-EBT for non-melanomatous skin cancers is encouraging in terms of short-term and long-term efficacy and convenience for non-operative patients. However, this technology needs further long-term follow-up to assess long-term local control, cosmesis, and late toxicity. Caution should be used when treating lesions on extremity sites, particularly in elderly patients, and more fractionated regimens should be considered to avoid severe acute toxicities.

\section{Disclosure}

The authors report no conflict of interest.

\section{References}

1. Gunderson LL, Tepper JE. Clinical radiation oncology. $3^{\text {rd }}$ ed. Elsevier Saunders, Philadelphia 2012; 757-769.

2. Gloster HM Jr, Brodland DG. The epidemiology of skin cancer. Dermatol Surg 1996; 22: 217-226.

3. Rogers HW, Weinstock MA, Harris AR et al. Incidence estimate of nonmelanoma skin cancer in the United States, 2006. Arch Dermatol 2010; 146: 283-287.

4. Siegel R, DeSantis C, Virgo K et al. Cancer treatment and survivorship statistics, 2012. CA Cancer J Clin 2012; 62: 220-241.

5. Veness MJ. The important role of radiotherapy in patients with non-melanoma skin cancer and other cutaneous entities. J Med Imaging Radiat Oncol 2008; 52: 278-286.

6. Hansen EK, Roach III M. Handbook of evidence-based radiation oncology. $2^{\text {nd }}$ ed. Springer, New York 2010; 3-13.

7. Leiter U, Garbe C. Epidemiology of melanoma and nonmelanoma skin cancer - the role of sunlight. Adv Exp Med Biol 2008; 624: 89-103.

8. Chahbazian CM, Brown GS. Radiation therapy for carcinoma of the skin of the face and neck. Special considerations. JAMA 1980; 244: 1135-1137.

9. Huynh NT, Veness MJ. Basal cell carcinoma of the lip treated with radiotherapy. Australas J Dermatol 2002; 43: 15-19.

10. Stoll HL Jr, Milgrom H, Traenkle HL. Results of Roentgen therapy of carcinoma of the nose. Arch Dermatol 1964; 90: 577-580.

11. Lederman M. Radiation treatment of cancer of the eyelids. Br J Ophthalmol 1976; 60: 794-805.

12. Petrovich Z, Kuisk H, Langholz B et al. Treatment results and patterns of failure in 646 patients with carcinoma of the eyelids, pinna, and nose. Am J Surg 1987; 154: 447-450.

13. Fitzpatrick PJ, Jamieson DM, Thompson GA et al. Tumors of the eyelids and their treatment by radiotherapy. Radiology 1972; 104: 661-665.

14. Del Regato JA, Vuksanovic M. Radiotherapy of carcinomas of the skin overlying the cartilages of the nose and ear. Radiology 1962; 79: 203-208. 
15. Parker RG, Wildermuth O. Radiation therapy of lesions overlying cartilage: carcinoma of the pinna. Cancer 1962; 15: 57-65.

16. Petrovich Z, Parker RG, Luxton G et al. Carcinoma of the lip and selected sites of head and neck skin. A clinical study of 896 patients. Radiother Oncol 1987; 8: 11-17.

17. Goldschmidt H, Breneman JC, Breneman DL. Ionizing radiation therapy in dermatology. J Am Acad Dermatol 1994; 30: 157-182; quiz 183-186.

18. Guibert M, David I, Vergez S et al. Brachytherapy in lip carcinoma: long-term results. Int J Radiat Oncol Biol Phys 2011; 81: e839-843.

19. Guinot JL, Rembielak A, Perez-Calatayud J et al. GECESTRO ACROP recommendations in skin brachytherapy. Radiother Oncol 2018; 126: 377-385.

20. Balgobind BV, Koedooder K, Zuniga DO et al. A review of the clinical experience in pulsed dose rate brachytherapy. Br J Radiol 2015; 88: 20150310.

21. Fritz P, Hensley FW, Berns C et al. Long-term results of pulsed irradiation of skin metastases from breast cancer. Effectiveness and sequelae. Strahlenther Onkol 2000; 8: 368-376.

22. Goyal U, Kim Y, Tiwari HA et al. A pilot study of ultrasound-guided electronic brachytherapy for skin cancer. J Contemp Brachytherapy 2015; 7: 374-380.

23. National Comprehensive Cancer Network. Basal Cell Skin Cancer (version 2.2021). http://www.nccn.org/guidelines/ guidelines-detail?category=1\&id=1416. Accessed May 25, 2021.

24. Ouhib Z, Kasper M, Calatayud JP et al. Aspects of dosimetry and clinical practice of skin brachytherapy: The American Brachytherapy Society working group report. Brachytherapy 2015; 14: 840-858.

25. Tom MC, Hepel JT, Patel R et al. The American Brachytherapy Society consensus statement for electronic brachytherapy. Brachytherapy 2019; 18: 292-298.

26. Shah C, Ouhib Z, Kamrava M et al. The American Brachytherapy society consensus statement for skin brachytherapy. Brachytherapy 2020; 19: 415-426.

27. Gauden R, Pracy M, Avery AM et al. HDR brachytherapy for superficial non-melanoma skin cancers. J Med Imaging Radiat Oncol 2013; 57: 212-217.

28. Khan L, Choo R, Breen D et al. Recommendations for CTV margins in radiotherapy planning for non melanoma skin cancer. Radiother Oncol 2012; 104: 263-266.

29. Ballester-Sánchez R, Pons-Llanas O, Llavador-Ros M et al. Depth determination of skin cancers treated with superficial brachytherapy: ultrasound vs. histopathology. J Contemp Brachytherapy 2015; 6: 356-361.

30. Bhatnagar A. Nonmelanoma skin cancer treated with electronic brachytherapy: results at 1 year. Brachytherapy 2013; 12: 134-140.

31. Ballester-Sánchez R, Pons-Llanas O, Candela-Juan C et al. Efficacy and safety of electronic brachytherapy for superficial and nodular basal cell carcinoma. J Contemp Brachytherapy 2015; 7: 231-238.

32. Podd TJ. Treatment of lower limb basal cell and squamous cell carcinomas with radiotherapy. Clin Oncol (R Coll Radiol) 1992; 4: 44-45.

33. Dupree MT, Kiteley RA, Weismantle K et al. Radiation therapy for Bowen's disease: lessons for lesions of the lower extremity. J Am Acad Dermatol 2001; 45: 401-404.

34. Cox NH, Dyson P. Wound healing on the lower leg after radiotherapy or cryotherapy of Bowen's disease and other malignant skin lesions. Br J Dermatol 1995; 133: 60-65.

35. Goyal U, Suszko J, Stea B. The feasibility of using ultrasound during follow-up for superficial non-melanoma skin cancers after electronic brachytherapy. J Contemp Brachytherapy 2017; 9: 535-539.
36. Freedman GM. Topical agents for radiation dermatitis in breast cancer: 50 shades of red or same old, same old? Int J Radiat Oncol Biol Phys 2014; 90: 736-738.

37. Fenton-Kerimian M, Cartwright F, Peat E et al. Optimal topical agent for radiation dermatitis during breast radiotherapy: a pilot study. Clin J Oncol Nurs 2015; 19: 451-455.

38. Boström A, Lindman H, Swartling C et al. Potent corticosteroid cream (mometasone furoate) significantly reduces acute radiation dermatitis: results from a double-blind, randomized study. Radiother Oncol 2001; 59: 257-265.

39. Hindley A, Zain Z, Wood L et al. Mometasone furoate cream reduces acute radiation dermatitis in patients receiving breast radiation therapy: results of a randomized trial. Int J Radiat Oncol Biol Phys 2014; 90: 748-755.

40. Hemati S, Asnaashari O, Sarvizadeh M et al. Topical silver sulfadiazine for the prevention of acute dermatitis during irradiation for breast cancer. Support Care Cancer 2012; 20: 1613-1618.

41. Jacobson G, Bhatia S, Smith BJ et al. Randomized trial of pentoxifylline and vitamin E vs standard follow-up after breast irradiation to prevent breast fibrosis, evaluated by tissue compliance meter. Int J Radiat Oncol Biol Phys 2013; 85 : 604-608.

42. Magnusson M, Höglund P, Johansson K et al. Pentoxifylline and vitamin $\mathrm{E}$ treatment for prevention of radiation-induced side-effects in women with breast cancer: a phase two, double-blind, placebo-controlled randomised clinical trial (Ptx-5). Eur J Cancer 2009; 45: 2488-2495.

43. Futran ND, Trotti A, Gwede C. Pentoxifylline in the treatment of radiation-related soft tissue injury: preliminary observations. Laryngoscope 1997; 107: 391-395.

44. Okunieff P, Augustine E, Hicks JE et al. Pentoxifylline in the treatment of radiation-induced fibrosis. J Clin Oncol 2004; 22: 2207-2213.

45. Aygenc E, Celikkanat S, Kaymakci M et al. Prophylactic effect of pentoxifylline on radiotherapy complications: a clinical study. Otolaryngol Head Neck Surg 2004; 130: 351-356.

46. Aygenc E, Celikkanat S, Bilgili $\mathrm{H}$ et al. Pentoxifylline effects on acute and late complications after radiotherapy in rabbit. Otolaryngol Head Neck Surg 2001; 124: 669-673.

47. Roth W, Beer RE, Iyengar V et al. Long-term efficacy and safety of superficial radiation therapy in subjects with nonmelanoma skin cancer: a retrospective registry study. J Drugs Dermatol 2020; 19: 163-168.

48. Barysch MJ, Eggmann N, Beyeler M et al. Long-term recurrence rate of large and difficult to treat cutaneous squamous cell carcinomas after superficial radiotherapy. Dermatology (Basel) 2012; 224: 59-65.

49. Goyal U, Pan J, Cui H et al. Does ultrasound measurement improve the accuracy of electronic brachytherapy in the treatment of superficial non-melanomatous skin cancer? J Contemp Brachytherapy 2017; 9: 14-19. 